\title{
REPARAÇÃO DA PAREDE ABDOMINAL ANTERIOR COM O OMENTO MAIOR
}

\author{
Repair of the anterior abdominal wall with omental flap
}

Alcino Lázaro da SILVA

Trabalho realizado no Departamento de Cirurgia da Faculdade de Medicina da Universidade Federal de Minas Gerais, Belo Horizonte, MG, Brasil.

DESCRITORES - Parede abdominal. Omento maior. Fechamento abdominal. Retalhos de pele.

\section{Correspondência:}

Alcino Lázaro da Silva, rua Guaratinga, 151, 30315-430, Belo Horizonte, MG

Fonte de financiamento: não há Conflito de interesses: não há

Recebido para publicação: 11/11/2010 Aceito para publicação: 08/04/2011

HEADINGS - Abdominal Wall. Omentum Majus. Abdominal closure. Skin graft.
RESUMO - Introdução - As perdas de substância da parede abdominal são substituídas por próteses sintéticas. Acontecem vantagens e desvantagens. O omento maior é uma estrutura totipotente e se aplica, também, à reparação. Objetivo - Apresentar possibilidade técnica de fechamento de parede abdominal com omento após ressecção da parte muscular. Método - Operou-se dois pacientes adultos com adenocarcinoma de colo direito invadindo a parede abdominal. Foi necessária a ressecção da metade direita da parede para fazer parte do monobloco. A metade esquerda do omento maior, remanescente, foi usada para vedar a cavidade abdominal através de sua sutura às bordas da ferida. Pôde-se recobrir com pele mobilizada nos flancos. A evolução foi satisfatória. No pós-operatório tardio formou-se hérnia incisional. Conclusão - O omento maior é um recurso a mais para reparar a perda parcial de parede abdominal.

ABSTRACT - Introduction - The loss of substance of the abdominal wall is usually replaced by synthetic prostheses with advantages and disadvantages. The greater omentum is a totipotent structure and can be applied also to this repair. Objective - To present technical possibility of abdominal closure after resection of abdominal wall muscle part with omentum. Method - The technic was carried out in two adult patients with colonic adenocarcinoma with invasion of the right abdominal wall. Was required the resection of the right half of the abdominal wall to join the en-bloc resection. The left half of the greater omentum was used to seal the abdominal cavity fixing it with sutures to the edges of the surgical wound. Final closure was done with the skin freed from the flanks. The recovery was satisfactory. In the late postoperative period incisional hernia occurred. Conclusion - The greater omentum can be used to repair the partial loss of the abdominal wall.

\section{INTRODUÇÃO}

reparação da parede abdominal quando há hérnias gigantes,
multirecidivadas ou recidivas volumosas já tem um recurso
técnico aceito pela comunidade cirúrgica. Faz- se a colocação de uma prótese (tela) grande que ultrapassa a área acometida ${ }^{1}$.

Quando há perda de substância por trauma ou ressecção oncológica da parede, o problema continua aberto e sem solução porque não se pode deixá-la aberta, a exemplo do que se faz na peritonite grave e generalizada (peritoniostomia). Coloca-se a prótese, mas quando ela não pode ser recoberta pela pele, fica exposta e traz grandes problemas para incorporar-se, pois a infecção é o mais provável a ocorrer. Sobre ela não se faz granulação eficaz quando não coberta pela pele, o que obriga a sua retirada ou troca periódica. A exposição e a rejeição exigem cuidado grande com curativos prolongados e caros, além de permanência hospitalar imprevisível.

Por isso, ocorreu a este autor mudar de tática e usar em duas oportunidades quase iguais, em adultos, no lugar da prótese o omento maior remanescente da ressecção oncológica. A apresentação dessa técnica é o objetivo deste trabalho. 
TÉCNICA

Ela foi utilizada em pacientes adultos, masculinos, portadores de adenocarcinoma de colo direito grandes, invadindo o íleo terminal e a parede abdominal local. Posteriormente e no interior do abdome não foram encontrados sinais macroscópicos de invasão tumoral. Isto mostrou nos dois pacientes que o tumor invadia a parede e não se estendendo para o retroperitônio. $O$ primeiro doente havia sido submetido à quimioterapia sem resultado. Ambos foram operados por duas vezes; o primeiro para ressecção da lesão tumoral incompleta e o segundo por suspeita de apendicite aguda complicada e com plastrão. Insucessos nas operações foi o que deve ter facilitado a invasão na laparotomia.

\section{O procedimento operatório}

Foi executada laparotomia medioabdominal direita com penetração na cavidade, medialmente ao acometimento parietal do tumor do ceco ou colo direito. Contornou-se a área acometida, colo direito e omento à direita, foi-se seccionando a parede, envolvendo todos os planos da pele ao peritônio. Feito esse contorno restava a massa tumoral ligada ao colo, omento e íleo terminal. Foi realizada secção de íleo, em margem de segurança, bem como do colo transverso e omentos, retirada em monobloco (Figuras 1 e 2) e anastomose íleo-cólica terminoterminal, em um plano extra-mucoso. Fez-se mobilização dermoepidérmica em torno da ferida para obter-se pele suficiente para aproximação e fechamento superficial da parede. Antes disto, o omento, na sua metade esquerda, isento de invasão tumoral foi mobilizado a fim de ser transferido parcialmente, para a direita, na extensão da abertura parietal. Finalisou-se com síntese em pontos separados dele à borda da ferida, em todo seu contorno. Com isto a cavidade ficou protegida por uma cortina omental (Figura 3). Sobre ele, fez-se a sutura de pele, borda a borda, em pontos separados fechando-se a parede. Se não houvesse pele suficiente, mesmo após a

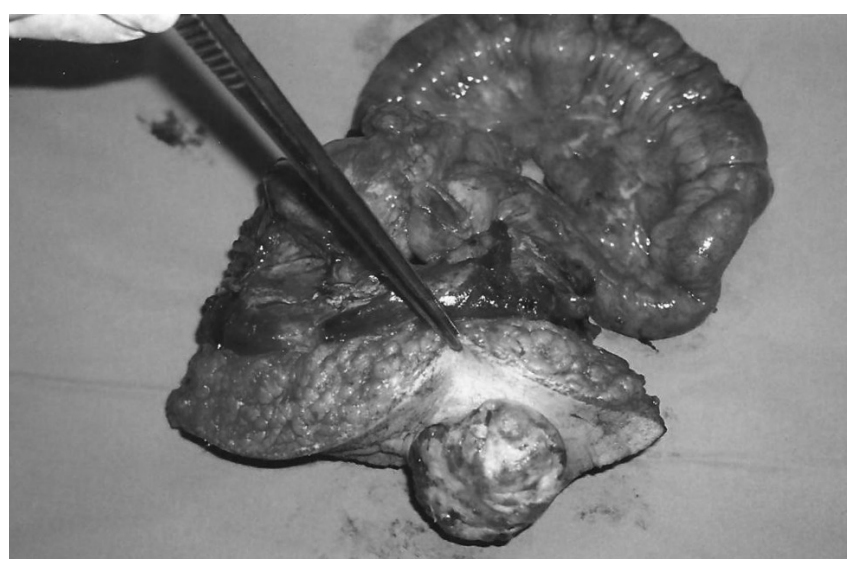

FIGURA 1 - Monobloco resultante da ressecção da parede abdominal anterior direita (pinça) do colo direito e do íleo terminal mobilização dermoepidérmica, fechar-se-ia o que fosse possível deixando o omento exposto. De uma forma ou de outra, foi efetuado curativo compressivo com faixa de crepom e imobilização dela com esparadrapo.

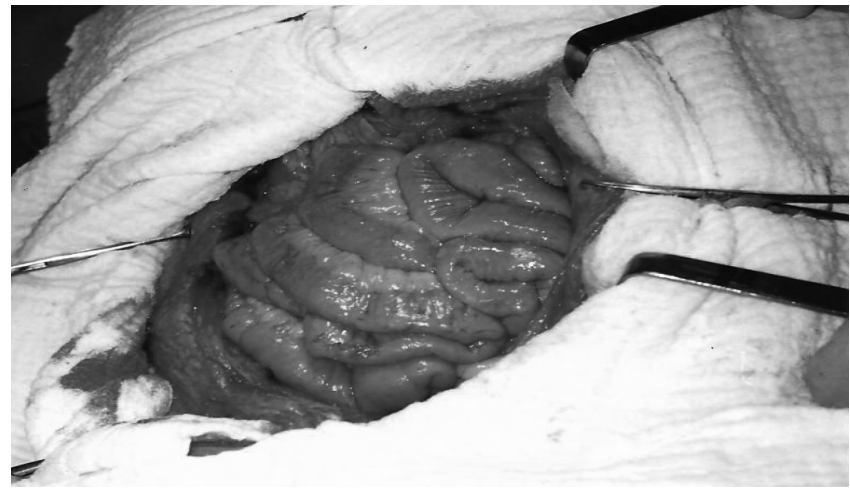

FIGURA 2 - Exposição das vísceras após a retirada da parede abdominal anterior direita

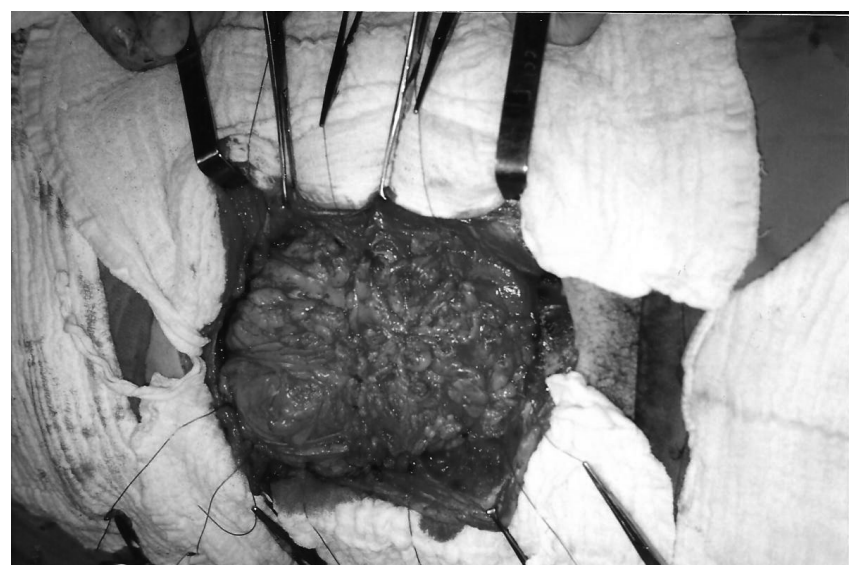

FIGURA 3 - A metade esquerda do omento maior, livre de doença, foi transferida para o lado direito e suturada às bordas da ferida operatória

O pós-operatório é preocupante por três motivos: evisceração, hipertensão abdominal e trombose. Para isto deixou-se cateterizada a bexiga, recostouse a cabeceira, estimulou-se movimentação delicada, exercícios respiratórios e dos membros inferiores. A evolução foi razoável, a parede granulou e a cicatrização consolidou-se, resultando em hérnia incisional, controlada por cinta adequada.

\section{DISCUSSÃO}

A ressecção da parede abdominal é incompatível com a vida. Quando se preserva metade dela é possível usar artifícios que facilitem a peritonização e depois a epitelização ou enxertia de pele.

Excetuando-se o risco de deixar vísceras 
expostas, sem reação peritoneal intensa como ocorre na peritonite, consegue-se recobri-las parcialmente e manter a laparostomia. Fatores agravantes impedem os recursos usados porque, ao pequeno aumento da pressão intra-abdominal, há evisceração. A pressão elevada por tosse crônica, omento gorduroso, falta de pele, bipedestação, esforços abdominais fisiológicos (constipação, micção) impedem qualquer tentativa de fechamento do abdome.

Na ressecção parcial há recursos e o mais aplicado, hodiernamente é a tela larga e extensa. Se ela possui a qualidade de, também, não provocar aderência que a fixe nas alças intestinais, melhor ainda. Mesmo sem pele para recobri-la é possível manter-se a tela exposta para posterior recuperação biológica. Isso exige muito cuidado e hospitalização prolongada, além dos riscos já apontados facilitando a evisceração.

Abstraindo-se do custo da tela e dos gastos hospitalares, ocorreu ao autor usar o omento remanescente de uma ressecção oncológica extensa da lesão, das alças próximas e da parede abdominal anterior direita invadida. Foi possível, mobilizando-se parcialmente o omento maior, na metade esquerda, preservada pela ressecção em monobloco, e trazendo-o para a metade direita, transformando-o na forma de uma cortina, suturada nas bordas da área cruenta. Naturalmente, essa situação é instável e sujeita a evisceração a qualquer esforço intra-abdominal.
Obtendo-se pele total por ampla mobillização bilateral, no plano pré-fáscia abdominal pôde-se recobri-la ainda que sob relativa tensão. Um curativo bem cuidadoso, com faixa de crepom, desde o tórax até a pelve pôde ser reforçado por faixas largas de esparadrapo, criando um colete que deixou a cavidade abdominal contida sem comprometer a capacidade respiratória e as funções abdominais fisiológicas.

A retirada da faixa foi feita com cuidado e na reposição, aos poucos, foi se afrouxando para não comprometer a pequena resistência que as suturas, tanto do omento quanto da pele, ofereciam no processo de cicatrização.

\section{CONCLUSÃO}

Esta observação autoriza a usar o omento maior, macroscopicamente isento de invasão tumoral, para tampar a abertura da parede abdominal, após ressecção parcial e facilitar a granulação e a epitelização. A hérnia incisional resultante não constitui problema e pode ser manuseada no futuro.

\section{REFERÊNCIA}

1. Silva AL. Hérnias, São Paulo. Editora Roca, 1992. 